\title{
AFRL-SR-AR-TR-02-0172
}

\section{Novel Corrosion Inhibition Methods For Aluminum Surfaces}

F49620-98-1-0307

John T. Yates

University of Pittsburgh

Approved for public release; distribution unlimited

Air Force Research Laboratory

Air Force Office of Scientific Research Arlington, Virginia 
REPORT DOCUMENTATION PAGE

1a. REPORT SECURITY CLASSIFICATION
UDCIaSS Ified
2a. SECURITY CLASSIFICATION AUTHORITY

2b. DECLASSIFICATION / DOWNGRADING SCHEDULE

4. PERFORMING ORGANIZATION REPORT NUMBER(S)

F49620-98-1-0307

6a. NAME OF PERFORMING ORGANIZATION

University of Pittsburgh 6b. OFFICE SYMBOL (If applicable)

AFRL-SR-AR-TR-02-

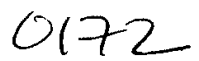

1b. RESTRICTIVE MARKINC

3. DISTRIBUTION/AVAILAEILITY CF REPORT

Approved for public release;

distribution unlimited.

5. MONITORING ORGANIZATION REPORT NUMBER(S)

7a. NAME OF MONITORING ORGANIZATION

b. ADDRESS (City, State, and ZIP Code)

6c. ADDRESS (Gty, State, and ZIP Code)

Department of Chemistry.' Surface Science Center

Pittsburgh, PA 15260

8a. NAME OF FUNDING/SPONSORING ORGANIZATION

AFOSR

SC ADDRESS (City, State, and ZIP Code)

Soi N. Randuph St, Rm-7.32

Artinfton vif $22203-1977$

11. TITLE (Include Security Classification)

Nove1 Corrosion Inhibition Methods for Aluminum Surfaces
12. PERSONAL AUTHOR(S) John T. Yates, Jr.

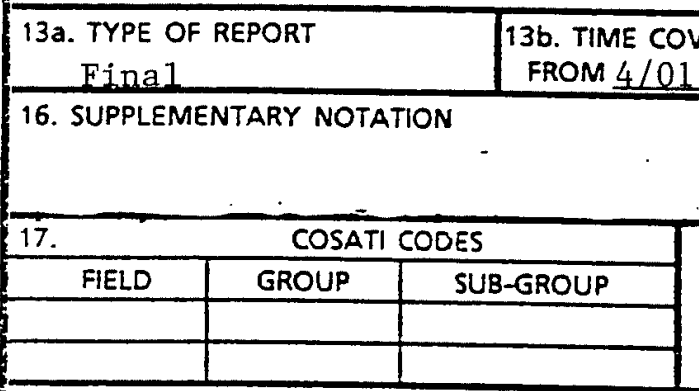

18. SUBJECT TERMS (Continue on reverse if necessary and identify by block number) aluminum, oxidation, corrosion passivation, non-thermal oxidation, ozone, electron impact, surface science

19. ABSTRACT (Continue on reverse if necessary and identify by block number)

The non-thermal activation of the oxidation of the $\mathrm{Al}(111)$ surface has been investigated. It has been found that compared to thermally grown $\mathrm{Al}_{2} \mathrm{O}_{3}$ films of equivalent thickness a factor of 10-30 increase in the resistance of oxide films may be achieved by the use of non-thermal activation methods such as electron bombardment of adsorbed water, electron bombardment of adsorbed $\mathrm{O}_{2}$ and $\mathrm{Al}_{2} \mathrm{O}_{3}$ clusters, and by oxidation by $\mathrm{O}_{3}$.

20. DISTRIBUTION/AVALLABILITY OF ABSTRACT $\square$ UNCLASSIFIEDNNLIMITED $\square$ SAME AS RPT. 22a. NAME OF RESPONSIBLE INDIVIDUAL John T. Yates, Jr.
21. ABSTRACT SECURITY CLASSIFICATION Unclassified

22b. TELEPHONE (Include Area COde) $22 \mathrm{C}$ OFFICE SYMBOL 412-624-8320 
Title: Novel Corrosion Inhibition Methods for Aluminum Surfaces

Principal Investigator: John T. Yates, Jr.

Inclusive Dates: 4/01/98 - 9/30/01

Contract/Grant Number: F49620-98-1-0307

Senior Research Personnel: Dr. Vladimir Zhukov

Professor Judith Yang

Dr. T. D. Burleigh

Dr. X. Chen

Professor J. G. Chen

Dr. H. D. Ebinger

Junior Research Personnel: Ms. Irene Popova, Ph.D. expected June 2002

Ms. Anya Kuznetsova, Ph.D., April 2001

Mr. V. Fomenko

Mr. G. Zhou

Publications: Fourteen papers have been published and one paper is yet to be submitted.

- A. Kuznetsova, T.D. Burleigh, V. Zhukov, J. Blachere and J.T. Yates, Jr. "Electrochemical Evaluation of a New Type of Corrosion Passivation Layer: Artificially Produced $\mathrm{Al}_{2} \mathrm{O}_{3}$ Films on Aluminum" Langmuir, 14, 2502 (1998).

- I. Popova and J.T. Yates, Jr. "Adsorption and Thermal Behavior of Benzotriazole Chemisorbed on $\gamma-\mathrm{Al}_{2} \mathrm{O}_{3}$ " Langmuir $\underline{13}, 6169$ (1997).

- H.D. Ebinger and J.T. Yates, Jr. "Oxidation of $\mathrm{Al}(111)$ by Electron Impact on Adsorbed $\mathrm{H}_{2} \mathrm{O}$ ” Surface Science, $\underline{412}, 1$ (1998).

- V. Zhukov, I. Popova, V. Fomenko and J.T. Yates, Jr. "Oxygen Adsorption on Al(111) Role of Surface Pretreatment in Governing Oxidation" Surface Science 441, 240 (1999).

- V. Zhukov, I. Popova and J.T. Yates, Jr. "Initial Stages of Al(111) Oxidation with OxygenTemperature Dependence of the integral Reactive Sticking Coefficient" Surface Science 441, 251 (1999). 
- I. Popova, V. Zhukov and J.T. Yates, Jr. "Electron-Stimulated Conversion of Chemisorbed $\mathrm{O}$ to $\mathrm{Al}_{2} \mathrm{O}_{3}$ on $\mathrm{Al}(111)$ " Applied Physics Letters $\underline{75}, 3108$ (1999).

- I. Popova, V. Zhukov, J.T. Yates, Jr. and J.G. Chen "Electron Stimulated Oxidation of $\mathrm{Al}(111)$ in $\mathrm{H}_{2} \mathrm{O}$ Vapor: Dipole Orientation Effects in the $\mathrm{Al}_{2} \mathrm{O}_{3}$ Thin Film" Journal of Applied Physics $\underline{86}, 7156$ (1999).

- I. Popova, V. Zhukov and J.T. Yates, Jr. "Role of Surface $\mathrm{Al}_{2} \mathrm{O}_{3}$ Clusters on the Kinetics of Al(111) Oxidation" Journal of Applied Physics 87, 8143 (2000).

- V. Zhukov, I. Popova and J.T. Yates, Jr. “ Delivery of Pure Ozone in Ultrahigh Vacuum" Journal of Vacuum Science and Technology A 18, 992 (2000).

- I. Popova, V. Zhukov and J.T. Yates, Jr. "Depth-Dependent Electrical Impedance Distribution in $\mathrm{Al}_{2} \mathrm{O}_{3}$ Films on $\mathrm{Al}(111)$ - Detection of an Inner Barrier Layer" Langmuir $\underline{16}, 10309(2000)$.

- A. Kuznetsova, J.T. Yates, Jr., G. Zhou, J.C. Yang and X. Chen "Making a Superior Oxide Corrosion Passivation Layer on Aluminum Using Ozone" Langmuir 17, 2146 (2001).

- A. Kuznetsova, I. Popova, V. Zhukov, J.T. Yates, Jr., G. Zhou, J.C. Yang and X. Chen "Making Superior Corrosion Resistant Aluminum Oxide Films Using OzoneElectrochemical and Electron Microscopy Studies" Journal of Vacuum Science and Technology A 19, 1971 (2001).

- V. Zhukov, I. Popova and J.T. Yates, Jr. "Electron-Stimulated Oxidation of Al(111) by Oxygen at Low Temperatures: Mechanism of Enhanced Oxidation Kinetics" Physical Review B 65, 195409 (2002).

- I. Popova, V. Zhukov and J.T. Yates, Jr. "Comparative Study of $\mathrm{Al}(111)$ Oxidation with $\mathrm{O}_{3}$ and $\mathrm{O}_{2}$ " submitted to Surface Science.

- I. Popova, V. Zhukov and J.T. Yates, Jr. "A Memory Effect in the Oxidation of Al(111)Enhancement of Oxidation Rate by Oxide Surface Charging," to be submitted.

\section{Novel Corrosion Inhibition Methods for Aluminum Surfaces}

\section{Objectives and Summary of Progress}

The goals of this project were to employ various methods of activation of oxygen to achieve the production of an aluminum oxide layer with enhanced corrosion passivation properties. A variety of methods of activation were employed-namely (1) The use of electron impact excitation; (2) The use of ozone for supplying an active form of oxygen; and (3) The use of surface charging to enhance oxidation kinetics. In some cases, electrochemical impedance spectroscopy was used to measure the impedance of the novel 
oxide layer and in all cases where energetic forms of oxygen were used, a 10-30 fold enhancement of film impedance was found, compared to thermally-grown film made in $\mathrm{O}_{2}$ and grown to equal thickness. Also, transmission electron microscopy was employed to evaluate the structure and density distribution function of the novel oxide layers produced. In addition, spectroscopic studies of the interaction of a corrosion inhibitor, benzotriazole, with aluminum oxide were carried out.

In order to carry out a portion of this work, an ozone generator, capable of directing a molecular beam of $97 \%$ ozone was constructed and tested. New procedures used to transmit almost pure ozone into a metal ultrahigh vacuum system were developed.

A number of important findings were discovered and these are listed below as one-line descriptions:

1. An enhancement of oxidation kinetics of $\mathrm{Al}(111)$ occurs when adsorbed $\mathrm{H}_{2} \mathrm{O}$ is bombarded by electrons. This is postulated to occur as a result of the production of $\mathrm{OH}$ radicals which are powerful oxidizers. NEXAFS studies indicated that polarized $\mathrm{Al}-\mathrm{O}$ bonds are produced in this process with a non random orientation in the normal direction.

2. Chemisorbed $\mathrm{O}$ atoms on $\mathrm{Al}(111)$ may be converted to oxide clusters by electron impact.

3. A method has been developed to study the depth dependent electrostatic field inside a dielectric layer such as $\mathrm{Al}_{2} \mathrm{O}_{3}$. This method showed that the largest electrical potential gradient occurs in the inner $7 \AA$ layer near the metal surface. It is postulated that this region is the crucial region for corrosion passivation.

4. Ozone was shown to cause an enhancement in the oxidation kinetics of $\mathrm{Al}(111)$ and to produce a superior corrosion resistance compared to $\mathrm{O}_{2}$. Transmission electron diffraction studies show that the oxide film produced by this method is $4 \%$ denser than an equivalent layer produced by oxygen. The initial sticking coefficient for ozone is 8.5 times higher than for oxygen on $\mathrm{Al}(111)$ at $300 \mathrm{~K}$. The dissociation of $\mathrm{O}_{3}$ is postulated to produce hyperthermal $\mathrm{O}$ and $\mathrm{O}_{2}$ species on the surface, leading to enhanced oxidation kinetics.

5. A very interesting memory effect has been found in which aluminum oxide clusters on an aluminum surface may be charged up by electron bombardment. This causes an enhanced rate of oxidation in the later stages of oxide film formation, and the effect is postulated to originate from enhancement of the ion mobility within the film as a result of the electric field produced within the film by the surface charging. 
Abstracts of the 15 publications originating from this work are given below:

- A. Kuznetsova, T.D. Burleigh, V. Zhukov, J. Blachere and J.T. Yates, Jr. "Electrochemical Evaluation of a New Type of Corrosion Passivation Layer: Artificially Produced $\mathrm{Al}_{2} \mathrm{O}_{3}$ Films on Aluminum" Langmuir, 14, 2502 (1998).

A recently developed technique for the artificial production of an $\mathrm{Al}_{2} \mathrm{O}_{3}$ film on ultrahigh-purity polycrystalline $\mathrm{Al}$ samples was employed. Electrochemical impedance spectroscopy (EIS), Auger electron spectroscopy (AES), and grazing angle X-ray diffraction (GAXRD) were used to investigate the artificial oxide film. The growth of aluminum oxide in water vapor $\left(5 \times 10^{-7} \mathrm{Torr}\right)$ enhanced by $100 \mathrm{eV}$ electron bombardment resulted in an artificial oxide film which exhibited a 10-30-fold improvement in electrical resistance in $3.5 \% \mathrm{NaCl}$ solution compared to oxide films of the same thickness grown at $300 \mathrm{~K}$ in the absence of electron bombardment (thermal excitation only). These measurements suggest that the artificial aluminum oxide film may provide superior corrosion passivation qualities compared to thermally grown oxide films. The amorphous nature of the artificial oxide film was confirmed by GAXRD.

\section{- I. Popova and J.T. Yates, Jr. "Adsorption and Thermal Behavior of Benzotriazole Chemisorbed on $\gamma-\mathrm{Al}_{2} \mathrm{O}_{3}$ ” Langmuir 13 , 6169 (1997).}

Adsorption experiments for benzotriazole, (BTAH) on the $\gamma-\mathrm{Al}_{2} \mathrm{O}_{3}$ surface were carried out at 150 and $293 \mathrm{~K}$. The thermal stability of the adsorbed layer was investigated. At low temperatures, adsorption results in the production of a thick condensed layer of BTAH. Strong intermolecular hydrogen bonds are observed. With increasing sample temperature, the BTAH molecules diffuse into the $\mathrm{Al}_{2} \mathrm{O}_{3}$ pore structure. Hydrogen bonding of the BTAH molecule specifically to isolated Al-OH groups is observed. Deprotonation of the BTAH molecule begins to occur through interaction, with the surface oxide anions near $300 \mathrm{~K}$. As a result of such deprotonation-type interaction the production of associated surface $\mathrm{OH}$ groups and of the $\mathrm{BTA}^{-}$anion are observed. The $\mathrm{BTA}^{-}$anion is bound to the surface Lewis acid site via a nitrogen atom lone pair. Extensive thermal treatment $(T=573$ $623 \mathrm{~K}$ ) causes decomposition of the adsorbed $\mathrm{BTA}^{-}$species, and modes related to the nitrogen ring disappear. After thermal treatment up to $873 \mathrm{~K}$, IR spectroscopy detects weak and broadened features of aromatic molecules on the surface. Auger spectroscopy of the sample after this thermal treatment shows that nitrogen containing species have disappeared whereas carbon remains. Infrared features due to aromatic residues persist to higher temperatures $(T=873-1023 \mathrm{~K})$. 


\section{- H.D. Ebinger and J.T. Yates, Jr. "Oxidation of Al(111) by Electron Impact on Adsorbed $\mathrm{H}_{2} \mathrm{O}$ " Surface Science, $\underline{412}, 1$ (1998).}

The oxidation of aluminum by electron bombardment of a water-covered surface at $90 \mathrm{~K}$ has been investigated by XPS, EELS and high-resolution electron energy-loss spectroscopy. Electron bombardment converts the adsorbed ice layer into a disordered aluminum oxide film with very high efficiency. The cross-section for water conversion is 2.5 $x 10^{-16} \mathrm{~cm}^{2}$ for an electron energy of $100 \mathrm{eV}$. The threshold energy of the electronic stimulation has been estimated to be $6 \pm 1 \mathrm{eV}$. The excitation probably proceeds via direct electron attachment, leading to dissociative production of an $\mathrm{OH}$ radical species, which is very effective for surface oxidation.

\section{- V. Zhukov, I. Popova, V. Fomenko and J.T. Yates, Jr. “Oxygen Adsorption on Al(111) - Role of Surface Pretreatment in Governing Oxidation" Surface Science 441, 240 (1999).}

The chemisorption of oxygen on the Al(111) surface was studied at 300-773 K using $\mathrm{X}$-ray photoelectron and high resolution electron energy loss spectroscopies. It was shown that extreme levels of $\mathrm{Ar}^{+}$bombardment and annealing pretreatment were necessary to prepare a surface with reproducible $\mathrm{O}_{2}$ adsorption behavior. The rate of oxygen adsorption was decreased after such a treatment. It is postulated that extensive bombardment/annealing yields a surface with a small number of defect sites. Predominantly chemisorbed $\mathrm{O}$ islands are formed even upon $300 \mathrm{~L}$ oxygen adsorption on this low defect density surface. These islands transform into oxide with time (at $300 \mathrm{~K}$ ) and increasing surface temperature $(\mathrm{T}=470$ $500 \mathrm{~K}$ ), producing a vibrational mode around $820-865 \mathrm{~cm}^{-1}$, characteristic of the oxide formation. Additional evidence for the assignment of this mode to the oxidic species is obtained from the experiments, where $\mathrm{O}_{2}^{-}$ion implantation or $\mathrm{Ar}^{+}$bombardment of a chemisorbed $\mathrm{O}$ layer were performed. The final oxide film produced after annealing of adsorbed $\mathrm{O}$ up to $600-650 \mathrm{~K}$ exhibits vibrational modes at ca 400,610 and $850 \mathrm{~cm}^{-1}$, in agreement with prior results.

\section{- V. Zhukov, I. Popova and J.T. Yates, Jr. "Initial Stages of Al(111) Oxidation with Oxygen-Temperature Dependence of the integral Reactive Sticking Coefficient" Surface Science 441, 251 (1999).}

The initial stages of $\mathrm{Al}(111)$ oxidation by oxygen were investigated using X-ray photoelectron spectroscopy (XPS) and high resolution electron energy loss spectroscopy (HREELS). The integral reactive sticking coefficient (S) was evaluated by measuring the $\mathrm{O}(1 \mathrm{~s})$ XPS peak area for exposures below $50 \mathrm{~L}$. Experiments were carried out at surface temperatures from 95 to $773 \mathrm{~K}$. The dissociative adsorption of $\mathrm{O}_{2}$ is proposed to occur by means of a molecular precursor mechanism leading to the non-monotonic behavior of $\mathrm{S}$ with changing surface temperature. The kinetics of $\mathrm{O}_{2}$ adsorption are governed by the strong temperature dependent balance of chemisorbed and oxidic species on the surface. Oxidic phase formation then influences the adsorption kinetics, by lowering the adsorption barrier 
from the precursor state (since stronger O-Al bonds are formed by oxide formation compared to chemisorption) and transforming the activated $\mathrm{O} 2$ adsorption process into a non-activated one. A rapid onset of the oxidic phase formation was found in the temperature range 473$573 \mathrm{~K}$ at these low exposures.

\section{- I. Popova, V. Zhukov and J.T. Yates, Jr. "Electron-Stimulated Conversion of Chemisorbed $\mathrm{O}$ to $\mathrm{Al}_{2} \mathrm{O}_{3}$ on $\mathrm{Al}(111)$ " Applied Physics Letters $\underline{75}, 3108$ (1999).}

The transformation of a chemisorbed $\mathrm{O}$ layer on the $\mathrm{Al}(111)$ surface into $\mathrm{Al}_{2} \mathrm{O}_{3}$ under electron impact has being monitored by High Resolution Electron Energy Loss (HREELS) and X-ray Photoelectron Spectroscopies (XPS). Electron irradiation (100 eV) of chemisorbed $O$ was observed to cause spectroscopic changes in the surface layer indicative of oxide formation. The energy transfer from the electrons to the chemisorbed $\mathrm{O}$ atoms through the electronic excitations, leading to vibrationally excited adsorbed particles, is proposed to be responsible for the observed conversion of chemisorbed oxygen to $\mathrm{Al}_{2} \mathrm{O}_{3}$. The cross section for this electron-induced process is estimated to be $2 \times 10^{-19} \mathrm{~cm}^{2}$ for $100 \mathrm{eV}$ electrons.

\section{- I. Popova, V. Zhukov, J.T. Yates, Jr. and J.G. Chen "Electron Stimulated Oxidation of $\mathrm{Al}(111)$ in $\mathrm{H}_{2} \mathrm{O}$ Vapor: Dipole Orientation Effects in the $\mathrm{Al}_{2} \mathrm{O}_{3}$ Thin Film" Journal of Applied Physics 86, 7156 (1999).}

The electron stimulated oxidation of $\mathrm{Al}(111)$ using $\mathrm{H}_{2} \mathrm{O}(\mathrm{g})$ as a source of oxygen has been investigated at $300 \mathrm{~K}$ using near edge $\mathrm{x}$-ray absorption fine structure (NEXAFS) and Auger electron spectroscopy. Irradiation with electrons $\left(100 \mathrm{eV}, 50 \mu \mathrm{A} / \mathrm{cm}^{2}\right)$ produced thick $\mathrm{Al}_{2} \mathrm{O}_{3}$ film layers (up to $15 \AA$ ), compared to the films grown thermally ( $4 \AA$ ) by the same water exposure. A preferential normal orientation of the O-Al bonds was found for the films grown by the electron assisted process, causing the O K-edge NEXAFS spectra to depend on the incident angle of the polarized $\mathrm{x}$-ray beam. In contrast, little polarization of the O-Al bonds was found for the case of $\mathrm{Al}_{2} \mathrm{O}_{3}$ films grown by thermal oxidation in $\mathrm{H}_{2} \mathrm{O}(\mathrm{g})$.

\section{- I. Popova, V. Zhukov and J.T. Yates, Jr. "Role of Surface $\mathrm{Al}_{2} \mathrm{O}_{3}$ Clusters on the

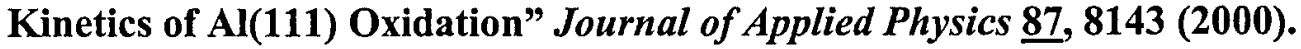

The effect of aluminum oxide clusters on the Al(111) surface on subsequent oxygen adsorption at $300 \mathrm{~K}$ was investigated for both low and high degrees of oxidation using X-Ray Photoelectron Spectroscopy (XPS) and High Resolution Electron Energy Loss Spectroscopy (HREELS). Oxide clusters on the Al(111) surface were produced by annealing chemisorbed $\mathrm{O}$ layers of various coverage up to $773 \mathrm{~K}$. Only the chemisorbed oxygen phase was found to form at $243-300 \mathrm{~K}$ after additional $\mathrm{O}_{2}$ exposure on surfaces containing both low and high oxide cluster populations. The chemisorbed $\mathrm{O}$ adatoms produced were not influenced by the oxidic phase, exhibiting spectroscopic features similar to those observed upon chemisorption on the clean surface without oxide clusters. Oxygen adsorption on the surface with both low and oxide cluster populations proceeded with the same rate as found on the clean $\mathrm{Al}(111)$ 
surface. The observed effect is postulated to be due to an increase of the number of the vacant $\mathrm{Al}$ adsorption sites liberated upon transformation of chemisorbed $\mathrm{O}$ adatoms into oxide clusters.

\section{- V. Zhukov, I. Popova and J.T. Yates, Jr. " Delivery of Pure Ozone in Ultrahigh Vacuum" Journal of Vacuum Science and Technology A 18, 992 (2000).}

An apparatus designed to produce and deliver pure ozone to a sample inside a metal ultrahigh vacuum apparatus is described. Ozone of $96-97 \%$ purity is prepared in a glass vacuum system and converted to a molecular beam of known flux using an all glass doser.. The storage lifetime of the $\mathrm{O}_{3}$ at Torr pressure in the glass storage vacuum system (containing a small surface area of metal) has been measured, and it is shown that the rate of decomposition $\mathrm{O}_{3}$ destruction during storage is inconsequential for hours of storage.

\section{- I. Popova, V. Zhukov and J.T. Yates, Jr. "Depth-Dependent Electrical Impedance Distribution in $\mathrm{Al}_{2} \mathrm{O}_{3}$ Films on $\mathrm{Al}(111)$ - Detection of an Inner Barrier Layer" Langmuir 16, 10309 (2000).}

A method to probe the depth dependence of the electrical impedance of an $\mathrm{Al}_{2} \mathrm{O}_{3}$ film on $\mathrm{Al}$ metal has been developed. The deposition of high electron affinity species $\left(\mathrm{O}_{3}, \mathrm{NO}_{2}\right.$, $\mathrm{Cl}_{2}$ ) at $90 \mathrm{~K}$ on the outer surface of an oxide film $(\mathrm{d}=20-25 \AA)$ on $\mathrm{Al}(111)$ produces negatively charged adsorbate molecules as a result of the trap-mediated electron tunneling from the metal. The capacitor produced in this way exhibits an electrostatic field gradient across the $\mathrm{Al}_{2} \mathrm{O}_{3}$ film which has been depth profiled by measuring the shifts in the $\mathrm{Al}^{3}+(2 \mathrm{p})$ and $\mathrm{O}^{2-}(1 \mathrm{~s}) \mathrm{X}$-ray photoelectron spectroscopy (XPS) features originating from the film. Analysis of the XPS peak shifts and shape variation shows that most of the potential gradient exists in the inner thin layer of $\mathrm{Al}_{2} \mathrm{O}_{3}(\mathrm{~d}=7 \AA)$ adjacent to the metal surface. We postulate that the inner oxide layer detected here is the crucial region for corrosion protection of $\mathrm{Al}$.

\section{- A. Kuznetsova, J.T. Yates, Jr., G. Zhou, J.C. Yang and X. Chen "Making a Superior Oxide Corrosion Passivation Layer on Aluminum Using Ozone" Langmuir 17, 2146 (2001).}

Aluminum oxidation by ozone produces an aluminum oxide layer which is superior in its corrosion properties compared to natural oxide, as measured by electrochemical methods. The electrochemically measured impedance of the $\mathrm{O}_{3}$-grown films is $\sim 10$ times greater than that of $\mathrm{O}_{2}$-grown films of equivalent thickness. An enhanced pitting potential is observed for the $\mathrm{O}_{3}$-grown oxide film. Transmission electron microscopy results show that the pore size of $\mathrm{O}_{3}$-grown oxide films is considerably smaller than that of $\mathrm{O}_{2}$-grown films. TEM electron diffraction studies show that the amorphous $\mathrm{O}_{3}$-grown films are $\sim 4 \%$ more dense than the $\mathrm{O}_{2}$-grown film. The initial sticking coefficient for ozone on atomically clean polycrystalline aluminum is 3.8 times larger than for oxygen at $300 \mathrm{~K}$. 
- A. Kuznetsova, I. Popova, V. Zhukov, J.T. Yates, Jr., G. Zhou, J.C. Yang and X. Chen "Making Superior Corrosion Resistant Aluminum Oxide Films Using OzoneElectrochemical and Electron Microscopy Studies" Journal of Vacuum Science and Technology A 19, 1971 (2001).

Aluminum surfaces have been subjected to oxidation at $300 \mathrm{~K}$, using a molecular beam of ozone of $97 \%$ purity. An enhancement of the kinetics of oxidation is found, compared to oxidation by $\mathrm{O}_{2}$. The oxide film produced exhibits enhanced corrosion resistance as measured by several electrochemical methods compared to comparable thickness oxide films made by oxygen exposure. Transmission electron microscopy measurements show that the ozone-grown films exhibit small pore sizes and also increased average density as measured by the behavior of the radial distribution function derived from electron diffraction measurements on films made from ozone and oxygen. These effects may be due to the lower oxygen vacancy defect density in films made from ozone. The special properties of ozone-grown aluminum oxide films are preserved even after the films are removed from vacuum and exposed to the atmosphere.

\section{- V. Zhukov, I. Popova and J.T. Yates, Jr. "Electron-Stimulated Oxidation of Al(111) by Oxygen at Low Temperatures: Mechanism of Enhanced Oxidation Kinetics" Physical Review B 65, 195409 (2002).}

The enhancement of the $\mathrm{Al}(111)$ oxidation rate by simultaneous oxygen exposures and electron irradiation was investigated at $90 \mathrm{~K}$ using X-ray Photoelectron Spectroscopy (XPS) and work function (WF) measurements. Electron beam energies of $\sim 0-100 \mathrm{eV}$ and current densities up to $80 \mu \mathrm{A} / \mathrm{cm}^{2}$ were used. No effect of electron irradiation was found at the initial stages of oxidation. The effect (enhanced oxidation rate) was only observed at higher $\mathrm{O}_{2}$ exposures (above $100 \mathrm{~L}$ ), when clusters of aluminum oxide were formed on the surface. The existence of a molecular $\mathrm{O}_{2}$ precursor state associated with these clusters is proposed, based on both the surface temperature and beam energy dependence of the oxidation rate. In addition, charge trapped on the oxide grains sets up an electrostatic field (detected by XPS and WF measurements) stimulating ion diffusion and further oxide film growth.

\section{- I. Popova, V. Zhukov and J.T. Yates, Jr. "Comparative Study of Al(111) Oxidation with $\mathrm{O}_{3}$ and $\mathrm{O}_{2}$ " submitted to Surface Science.}

The interaction of $\mathrm{O}_{3}$ and $\mathrm{O}_{2}$ with the $\mathrm{Al}(111)$ surface was investigated over the surface temperature range of 90-600 K using X-ray Photoelectron Spectroscopy (XPS). The oxidation of aluminum at $300 \mathrm{~K}$ with ozone gas was found to proceed with an 8.5 times higher initial sticking coefficient compared to oxygen, reaching a 2-2.3 times higher saturation oxide layer thickness of approximately $20 \AA$. The enhanced oxidation rate observed at lower temperatures indicates that trapping of the molecular ozone species into a shallow precursor well occurs in the course of $\mathrm{Al}(111)$ oxidation. The difference in activation energy for $\mathrm{O}_{3}$ adsorption and desorption to and from this state is $\left(E_{d}-E_{a}\right)=7 \pm 2 \mathrm{meV}$. 
Consequent dissociation of the ozone molecules on the surface is proposed to proceed by the formation of hyper - thermal $\mathrm{O}_{2}$ and atomic $\mathrm{O}$ species. The additional energy supplied to these species favors an oxidation mechanism involving preferential direct formation of $\mathrm{Al}_{2} \mathrm{O}_{3}$ clusters. In contrast, for oxidation with molecular oxygen, the formation of a chemisorbed $\mathrm{O}$ phase, followed by its slow transformation into oxide clusters, is observed. The higher electron affinity of the ozone molecule compared to oxygen is proposed to also enhance the kinetics of Al oxidation at the later stages of the oxide layer growth (film thickness $d \geq 2-3$ $\mathrm{ML}$ ), by enhanced tunneling of electrons from $\mathrm{Al}$ metal to the adsorbed $\mathrm{O}_{3}$. Tunneling electrons create an electrostatic potential across the growing film, stimulating ion-diffusion and, thus, oxide film growth.

\section{- I. Popova, V. Zhukov and J.T. Yates, Jr. "A Memory Effect in the Oxidation of Al(111)-Enhancement of Oxidation Rate by Oxide Surface Charging," to be submitted.}

The presence of an uncompensated electrostatic charge on the surface of a growing $\mathrm{Al}_{2} \mathrm{O}_{3}$ film was shown to increase the oxidation rate and to allow additional oxide formation upon consequent exposures to $\mathrm{O}_{2}$ at $90 \mathrm{~K}$. We have demonstrated that irradiating an $\mathrm{Al}_{2} \mathrm{O}_{3}$ film grown to saturation with an electron beam $\left(E_{p}=100 \mathrm{eV}, I_{p}=5 \mu \mathrm{A} / \mathrm{cm}^{2}\right)$ results in the creation of an electrostatic potential difference across the film $(\mathrm{V} \approx 1-1.5 \mathrm{eV})$. The potential can be created (by electron irradiation) and removed (by annealing up to $723 \mathrm{~K}$ ) reproducibly, indicating simple electrostatic charging of the insulator oxide film. The presence of the electrostatic potential gradient was detected by the $\mathrm{O}(1 \mathrm{~s})$ and $\mathrm{Al}(2 \mathrm{p}) \mathrm{XPS}$ peak shift and surface work function change, and is found to enhance the oxidation rate upon additional $\mathrm{O}_{2}$ exposures. Removal of the field in the process of additional oxidation gradually decreases the observed oxidation rate. We postulate that the electrostatic field across the thickness of the oxide film stimulates ion diffusion - the rate-limiting step of the oxide growth process. Effects of the electrostatic field on the $\mathrm{O}_{2}$ dissociation rate, enhancing oxidation, are also discussed. 